\title{
Discussing Atypical Sexual Harassment as a Controversial Issue in Bystander Programmes: One UK Campus Study
}

\author{
Helen Bovill ${ }^{1}$ (D) $\cdot$ Richard Waller $^{1}$ (D) $\cdot$ Kieran McCartan $^{2}$
}

Published online: 14 December 2019

(c) The Author(s) 2019

\begin{abstract}
This research emanates from an anti-sexual violence bystander programme delivered at an English university. Fifteen students were identified through purposive and convenience sampling to take part in focus groups. Discussions emerged regarding atypical sexual harassment. There is a gap in the literature exploring sexual harassment outside of the male perpetrator and female victim narrative which this paper contributes to. This paper considers four conversational themes: 'unwanted touching: women to men', 'sexual banter: women to men', 'sexual stereotypes: women and men', and 'developing stronger ethical subjectivity'. This paper recognises most sexual harassment occurs from men to women, and acknowledges criticism of focussing otherwise when resources are limited, noting this risks obscuring the enduring power differentials between the sexes. It contends that exploring a controversial issue, such as male experience of sexual harassment, might help bystander programmes by developing ethical subjectivity in undergraduate students. Exploring sexual behaviour as a spectrum may lead to counter hegemonic discourses to emerge.
\end{abstract}

Keywords Ethical subjectivity $\cdot$ Sexual spectrum $\cdot$ Counter hegemony

\section{Introduction}

In 2017 Revolt Sexual Assault conducted a survey receiving 4491 responses from 153 UK institutions and found ' $70 \%$ of female and $26 \%$ of male students and recent graduates' have experienced sexual violence (Revolt Sexual Assault 2018, p. 4).

Helen Bovill

Helen2.bovill@uwe.ac.uk

1 Department of Education and Childhood, Faculty of Arts, Creative Industries and Education (ACE), University of the West of England, Frenchay Campus, Coldharbour Lane, Bristol BS16 1QY, England

2 Faculty of Health and Social Sciences, University of the West of England, Frenchay Campus, Coldharbour Lane, Bristol BS16 1QY, England 
These statistics draw attention to a UK university issue which replicates similar findings in other countries such as the US (Cantor et al. 2019). It also draws attention to the range of terms used. Sexual violence is an all-encompassing term used to describe a spectrum of sexual behaviour from cat-calling, offensive sexual jokes, and unwanted touching, through to stalking and rape. Many other terms are used to consider this arena, for example, sexual abuse which can include unwanted physical and non-physical contact, or sexual assault which refers to unwanted physical sexual contact, for example touching or kissing (NIdirect, n.d.). Sexual harassment also refers to unwanted sexual behaviour, it is unlawful under the Equality Act 2010 and defined as:

When a person engages in unwanted conduct of a sexual nature that has the purpose or effect of: violating someone's dignity, or creating an intimidating, hostile, degrading, humiliating or offensive environment for them (Equality and Human Rights Commission 2017, p. 2).

The words intimidation, hostility, degradation, humiliation and offense are important here and encapsulate some of the discussion points identified in the research underpinning this study and considered later by Cantor et al. (2019). Though problematic, what all of these terms have in common is, they represent 'sexual behaviour you don't want to do, don't agree to do or don't understand' (NIdirect, n.d. p.1). The term sexual violence or (SV) will be adopted throughout this paper when referring to the spectrum of sexual harm. The term sexual harassment or $(\mathrm{SH})$ will be used when referring specifically to unwanted sexual touching or commenting.

Exploring this range of terms also identifies issues in data comparability across time and space. One of the widest sources of international data to measure campus SV are Campus Climate Studies (CCS) which are tools to measure the sexual climate on campus, including prevalence and awareness of SV, and response and support for this. They were established on many US campuses after the Not Alone Report (White House Task Force (WHTF) 2014) of the Obama administration, but they are not widely established in the UK. US data from CCS points to SV and SH as an enduring campus issue, with statistics representing greater awareness rather than escalation (Cantor et al. 2019). These statistics, though problematic, potentially represent just the tip of the iceberg (Yung 2015; Kemble and Chettiar 2018). In lieu of similar measurement tools in the UK and elsewhere currently it can be assumed, due to similar cultural contexts, that this is representative of the UK also, where what we know about campus SV in general and SH specifically potentially represents underreporting, and raised awareness rather than escalation, and under-reporting.

UK universities have responded to a growing awareness of SV on campus as an issue by developing more than 60 different projects from a Higher Education Funding Council for England (HEFCE 2018) £2.4 million Catalyst Fund, some of which implemented bystander programmes. Bystander is a programme developed from the US and focusses on assisting students to notice an event as problematic, developing skills to intervene before, during or after an event, with intentions of distracting from, stopping, or minimising SV. It aims to support students to move from passive bystanders to pro-social active bystanders (Banyard 2011). 
This paper reports qualitative findings from research focus groups, which resulted from one of the HEFCE funded projects. This particular project delivered an eight hour bystander programme to undergraduate students (developed by Fenton et al. 2014). Each session was delivered by a trainer working with students in groups of 10-20 in seminar environments. Students self-selected to take part. The bystander programme included introduction to bystander theory, gender norms, rape myths, consent, definitions of sexually harmful behaviour, and consequences for perpetrator and victim. It also included practical elements, through role playing bystander actions in potential scenarios of SV. A sub set of the students who opted to receive the bystander programme make up the fifteen students discussed in this paper who later took part in research focus groups (discussed in detail in "Methods" section).

Although SH occurs mainly from men to women, it also occurs across the sexes. Same sex SH has an emerging body of literature (e.g. Forsman 2017; Ioannou et al. 2017), and SH toward those presenting or appearing to present as outside of heterosexuality, marginally explored too (e.g. Paulk et al. 2017; Cantor et al. 2019; Johnson and Otto 2019). A gap in the literature exists when exploring perceptions of SH from women toward men in what appears to be within heteronormative contexts. This paper aims to contribute to this gap for the following reasons:

1. Discussions of SH across the sexes arose in focus group conversations and a job of research is to present unusual data, however uncomfortable it may be. Uncovering that discomfort can also be enlightening.

2. Exploring women as capable of SH toward men, and men as vulnerable to $\mathrm{SH}$ from women unpicks stereotypical understandings of sexual behaviour, where women are seen only as passive and pacifying and men only as sexually primed predators.

3. Challenges to toxic and hegemonic understandings of sexual behaviour, the bedrock of so much SV, can emerge as a result of unpicking stereotypes.

4. A framework of stronger sexual ethics and increases to ethical subjectivity in undergraduate populations may, in turn, be encouraged.

\section{Typical and Atypical Sexual Harassment}

The origin of the definition of $\mathrm{SH}$ is unclear. It tends to be discussed as emerging from within a working context (slavery, domestic service etc.) and in relation to women as victims through contexts in which men impose sexual relations upon women in their service. More secure law, in the West, began to arise in the 1970s through social movements where sex discrimination was made unlawful. Specific legislation for SH arose in the 1990s in the UK in the Protection from Harassment Act 1997. SH is unlawful under the Equality Act 2010 and it covers a range of behaviours including, for example, sexual commenting, unwelcome touching, sexual assault, stalking, and offensive communications.

McDonald and Charlesworth (2015, p. 118) refer to 'harassment by men towards men and by women towards men or other women' as 'atypical forms of 
sexual harassment'. Their workplace study found that while most SH research 'involves a male harasser and a female target, men are the target of SH far more commonly than typically understood' (McDonald and Charlesworth 2015, p. 119). For example in 20172000 online interviews were conducted with UK workers finding 'one in five women had been sexually harassed in the workplace', seven percent of men also responded as victims of SH at work (Opinium 2017, p. 1). Studies into atypical $\mathrm{SH}$ are few, tend to treat male and female experiences similarly and find, "men who report SH effectively violate expectations of what men usually do and are consequently disbelieved or criticized' (McDonald and Charlesworth 2015, p. 121). For example, this may go against hegemonic masculinity norms associated with men such as a generalised belief that men are biologically primed for sex, they have a right to sex, and women must take the leading role in keeping the male sex drive under control (World Health Organization 2009).

Exploring statistics on $\mathrm{SH}$ is comparably difficult as parameters of $\mathrm{SH}$ are complex to define and different studies use different terms. Accessing statistics on atypical SH is also difficult as much research explores this only in relation to men as perpetrators and women as victims. Where statistics are considered more broadly, they are often not broken down to aid greater understanding of what form the $\mathrm{SH}$ takes, or who is perpetrating against whom. Understanding statistics regarding atypical SH from women to men in a university context is equally difficult as it is an underresearched area. Revolt Sexual Assault (2018) states that 26\% of male students and recent graduates' have experienced SV but there is no further detail on this, so it is not possible to know what percentage of this is male to male or female to male perpetration, or what this SV constitutes. The charity DrinkAware conducted research into the impact of alcohol in England and Wales, including students in its survey to 2004 participants aged 18-29. Results were isolated to 18-24 year olds accounting for 1853 of the sample. It found:

nearly a third of young women (31\%) and 1 in 10 young men (11\%) aged 18-24 said they received inappropriate or unwanted physical attention or touching on a drunken night out' (DrinkAware 2018, p. 3).

The prior qualitative phase of the DrinkAware research involved up to 90 participants in different phases of interviews and workshops. The study determined that young men experience 'uninvited molestation by women, although they appear to be unlikely to describe it as unpleasant' (Christmas and Seymour 2014, pp. 9-10). This begins to open up debates toward forms of atypical $\mathrm{SH}$, however in so doing it plays back into hegemonic norms by declaring, without further explanation, that men are 'unlikely to describe it as unpleasant'. This finding is contradicted in the study for this current paper.

As previously mentioned, American universities have a larger database of statistical data regarding campus SV, than UK universities, due to the use of CCS. In 2019 The Association of American Universities conducted the largest CCS study of its kind gaining 181,752 responses from across US institutions, from a broad student sample including women, men and students identifying as Trans, non-binary, gender queer or gender questioning (TGQN). When assessing the chapter dedicated to SH 
(Cantor et al. 2019, pp. 45-50) overall $41.8 \%$ of students experienced at least one type of $\mathrm{SH}$ from the following list:

- Offensive sexual remarks, jokes, stories

- Offensive comments about your or some else's body, appearance, sexual activities

- Said crude or gross things to you or tried to get you to talk about sexual matters when you didn't want to

- Used social or on-line media to send offensive sexual remarks, jokes, stories, pictures, videos to you; or communicated these about you in these ways

- Continued to ask you to go out, get dinner, have drinks or have sex even though you said, "No?"

This data was broken down in detail in tables (Cantor et al. 2019, pp. A7-1 to A7-125), for example, analysing via female, male and TGQN characteristics:

- How many people behaved toward you like this

- Number of times

- Association to university, e.g. student, instructor, research staff, coach, alumni

- Intimately involved or not

- Sexuality, ethnicity, disability.

This represents a step in the right direction, however whilst it is possible to identify that $59.2 \%$ of undergraduate women and $36.2 \%$ of undergraduate men experienced at least one type of SH (Cantor et al. 2019, p. A7-59) it is still not possible to verify if the perpetrators are male or female.

In considering the controversial issue of atypical $\mathrm{SH}$, this current paper remains clear that $\mathrm{SH}$ is perpetrated most often from males towards females. In fact, one reason to explore atypical $\mathrm{SH}$ is to further highlight that women and girls remain the most likely victims. This paper does not seek to marginalise or downplay the extent of SH that women are subjected to at the hands of men. Neither is it engaging with debates around SH from men against men; or non-binary, transgender or genderqueer experiences. Though this is in great need of further research, space does not allow to develop this argument here. However, by not engaging with discussions of atypical $\mathrm{SH}$ from women toward men we miss an opportunity to further understand how hegemonic norms frame and drive SH. Blunt (2015, p. 4) draws attention to this in that whilst men are much more infrequently victims of SH it does not 'mean the results of such actions cannot have a profoundly negative effect'.

\section{Sexual Behaviour as a Spectrum}

Zalewski et al. (2018) discuss how SV against men has been ignored in war and peace and note that fear of diversion of limited resources might, understandably, be one reason that underpins this. They also highlight fears that inclusion of men in this discourse may mask male hierarchy, power and domination. Alternatively, 
they argue leaving men out of the conversation further contributes to an already partial and unstable knowledge of SV against women.

Heidensohn $(1985,1989,2010)$ states it is surprising there is a lack of empirical focus on 'deviant' sexual behaviour within half of society-women. She states a more meaningful approach is needed to understand women and mens' sexual behaviour. Heidensohn develops the theory of 'double deviance' where deviance in women is either ignored, inflated, or excessively punished because it challenges our fundamental understandings of human sexual behaviour. It also contributes to a lack of understanding of female sexual behaviour both in its own right and in relation to men's sexual behaviour and the contexts from which they emerge. Women are most often viewed as being sexually passive and having a pacifying effect upon male sexuality and where they move away from this, it is either ignored or constructed more negatively than in men. Viewing women only in sexually passive or submissive ways and men only in sexually aggressive or dominant ways does nothing to challenge dichotomous or binary understandings of masculine hegemony.

Everitt-Penhale and Ratele (2015) explore the role of ideology in constructing 'traditional' notions of masculinity which can lead to men adhering to culturally defined standards of male sexual behaviour such as flouting risk, aggressiveness, and a tendency to see relations between the sexes as adversarial. They caution that failing to acknowledge these ideological functions may contribute to a lack of challenge to these discourses.

Bryan (2019) helps to further clarify this by drawing on Connell's (1995) work on masculinities, considering how research can misread, ignore or devalue multiple masculinities (in Bryan's case through exploring black boys' engagement in play). Bryan considers that in highlighting aspects of masculinity that might be viewed as 'less masculine', and considering this instead as 'valued male traits' it is possible to disrupt ideologies which contribute to toxic and harmful stereotypes associated with traditional notions of masculinity. This current paper will draw on Bryan's work to explore how valuing the vulnerability in men's sexual responses to atypical SH from women could contribute to a more nuanced understanding of sexual behaviour and how it plays out across a complex spectrum.

Equally, a narrow view of what constitutes femininity and women's sexual behaviour ignores that it too spans a complex spectrum. Bay-Cheng (2015, p. 279) refers to how women's sexual behaviour has often been explored and judged upon a 'moralist continuum of sexual activity ranging from virtuous (virgins) to licentious (sluts)'. Though the virgin slut continuum may have shifted in the West in more recent years, this judgement persists. In hegemonic and heterosexual relations between the sexes "women are sanctioned if they do not court male sexual interests to some degree, but may be called teases for provoking without satisfying male sexual desires' (Bay-Cheng 2015, p. 281). Bay-Cheng (2015) notes that one-dimensional models cannot account for the ways in which norms influence women's sexual behaviour. Women's agency will be explored in this paper using Bay-Cheng's (2015) agency line, or the extent to which women have control and are controlled regarding their sexual behaviour. 
This paper will explore these relational complexities between the sexes as those who fall outside of dominant notions of sexual behaviour are not adequately captured in much theoretical debate. A stronger multi-dimensional analysis of the complexities of sexual behaviour is required to move debates forward, and this also includes engaging with uncomfortable debates such as atypical $\mathrm{SH}$ from women to men.

\section{Ethical Subjectivity}

Pastor (2014, p. 17) proposes that prevention programmes explore 'subjective vulnerability and relational complexity' to enable the development of stronger sexual ethics. Katz et al. (2011), Katz (2018) and Miller (2018) consider bystander approaches to violence prevention. They have been critical of sex neutral approaches, not least because of an increasing number of studies in the United States on female perpetrated intimate partner violence and mutual aggression' (Miller 2018, p. 1786). Instead, the approach they highlight is concerned with social justice, which challenges existing patriarchal structures and prevalent sex norms and focuses on benefits of transformative approaches. This involves developing critical analytic skills in young people to question behaviour and attitudes that conform to rigid and stereotypical norms.

Carmody (2009) also draws attention to issues with prevention programmes which focus primarily on normative sex relations where all men are represented as dangerous and invulnerable and women as 'victims in waiting' without agency. Carmody (2009) discusses the importance of developing ethical subjectivity in young people, defined as the 'skills to reflect on their own ethical stance in relation to themselves and others' (Carmody 2009, p. 8) advocating programmes which provide the conditions for this to develop. Pastor (2014, p. 10) concurs noting 'a binary model of sexual power is itself responsible for widespread sexual violence'.

Considering men as vulnerable to $\mathrm{SH}$ and women as capable of perpetration goes against what we understand as behaviour between the sexes. However, controversial issues explored in a supportive environment can increase attention and engagement, lead to appreciation of diversity of experience, allow for expression of fears, develop skills of listening and empathy, and can increase student activism (Johnson and Johnson 2009). This can also be a vehicle through which 'ethical subjectivity' is increased.

Critical thinking and development of ethical subjectivity may enable deeper understandings of underlying structures aligned with what is sometimes termed a 'social justice' approach to prevention work (Miller 2018) where unexamined traditions and structural inequalities, as well as individual responses are deconstructed. Pastor (2014, p. 16) calls for prevention programmes to develop a framework of sexual ethics where participants are enabled to develop tools to act as 'accountable and caring sexual subjects'. Exploring alternative patterns of behaviour between the sexes might contribute to this. 


\section{Methods}

This study explores qualitative focus groups. The first focus group consisted of five female students, the second, five females and two males, the third, two females and one male; totalling fifteen participants. Focus groups lasted between two and three hours, were audio recorded and transcribed. Focus groups were chosen because the researchers wanted to draw out beliefs, experiences attitudes, values and reactions; surveys are less useful for this (Cohen et al. 2011). Focus groups enabled the gathering of a lot of data in a short space of time that interviews would have been more time costly to produce. Ochieng et al. (2018) draw attention to data saturation in focus groups where a sequence of up to three focus groups should be conducted. This research instead, carried out one focus group with each group for a longer period of time than is usual, of two to three hours.

Ochieng et al. (2018) also draw attention to issues of focus group fatigue. The relevance of the topic to the lives of participants seemed to manage this. The focus group was broken up within a semi-structured framework consisting of introductions, where information sheets and consent forms were revisited, followed by a series of potential themes for discussion determined in a focus group guide directed by a literature review. Examples of questions asked were "what key messages stood out for you within the bystander programme?' and 'what do you consider to be healthy/unhealthy social norms in terms of relationship and sexual behaviour?' This was followed by a series of phrases being shown to participants via PowerPoint and taken from a range of already existing social norms campaigns, example phrases were 'students know it's not ok to grope someone without their consent' and 'drinking is not a crime, rape is'. Participants were given the opportunity to ask further questions and a range of support services handed out at the end.

Two authors of this paper conducted the focus groups. The first author (cis female) led the focus group. The second author (cis male) made detailed observations. Focus groups allowed for potential power imbalances to be managed as within a focus group the researcher ideally becomes a 'facilitator' moderating peripherally in a way less likely in a one-to-one interview (Ochieng et al. 2018). Most importantly focus groups allow for the group dynamic to emerge. Group dynamic needs to be managed by facilitators as focus groups have a tendency for stronger voices to take over, they can also lead to views being suppressed through the power of the group (Femdal and Solbjør 2018). Having two researchers conduct the focus groups meant they could move between roles of facilitator, note-taker, lead questioner, notice when members took over or were left out, and moderate accordingly.

\section{Sampling}

Participants were sampled through non probability sampling techniques because the sampling frame was too small for randomisation at approximately $(n=200)$ students who took part in a bystander programme in one year group, at one post-92 UK university having a total student population of $>(n=30,000)$. Researchers contacted participants who took part in any of the bystander programme, and consented to 
further contact. This produced a homogenous purposive sample as students were deliberately chosen because they had knowledge and experience of the phenomena under study and shared similar traits such as age range and life experience. We accepted all of those who agreed to take part, thus participant willingness and availability also makes this a convenience model (Etikan et al. 2016). The researchers acknowledge bias in these sampling techniques due to researcher subjectivity and self-selection. Also sample size was small, as such inference and generalisability are not overtly claimed outside of 'fuzzy' or propositional generalisation (Bassey 1998).

\section{Analysis}

All three authors of this paper were involved in analysis. This paper used thematic analysis and Braun and Clark's (2006) recommended steps of: data familiarisation, generation of initial codes, searching, reviewing, defining, naming, and reporting themes. After an initial separate analysis stage reading all data for familiarisation, all authors met to compare and contrast initial findings generating initial codes, some of which later became reported themes for other papers. In this first meeting the three researchers began to assign initial codes. They then independently colour coded different sections of the transcripts via Microsoft word searching for the codes they were assigned in greater depth. In further joint meetings, in person or electronically, prominent themes were established and less prominent ones dismissed, dependent on their re-occurrence in the data, resulting in defining, naming and reporting themes. Constant comparison of transcripts led to some powerful findings to emerge one of which was perceptions of 'atypical SH' represented in this paper.

\section{Data Protection and Ethics}

In line with current university protocol and General Data Protection Regulation (2018), focus group recorded data was immediately transferred and stored on password protected computers and deleted from recording devices. Transcript data was emailed via password protected one drive files to a university registered transcriber.

University ethics board permission was granted (ethical approval reference number: UREC17.08.02). Conditions were placed on approval which included: exclusion if under eighteen, inclusion of sources of support, explanation of disclosure processes, a constant named contact throughout the research, and setting up an advisory group to oversee process. Participants received information and consent sheets detailing the research, right to withdraw, confidentiality, anonymity and data protection processes. They received this information at the sampling stage, re-iterated at data collection. This included a privacy statement about keeping what was discussed in the focus groups confidential. Consent forms for the focus groups clarified that participants were unable to withdraw their individual data once focus groups were completed as, due to the group nature of focus groups this would impact on other participant data. However, participants were given the right to withdraw their 
participation during the focus groups. British Educational Research Association (BERA) (2018) guidelines informed the research process.

\section{Data Presentation and Discussion}

Participants identified six prevalent areas that were of concern: issues with consent, lack of awareness of domestic abuse, worries about initiation and humiliation ceremonies, inappropriate use of social media, and normalisation of unwanted touching. The focus of this paper is upon 'unwanted touching' and complexities around the ways that men may experience and respond to this and associated behaviour, such as sexual comments, from women. This has been divided into four conversational themes:

1. Unwanted touching: women to men.

2. Sexual banter: women to men.

3. Sexual stereotypes: women and men.

4. Developing stronger ethical subjectivity.

Though SH from women towards men was not identified as a subject for discussion in the focus group interview guide used by the researchers, this emerged unprompted by some participants. It opened up surprisingly thoughtful and level-headed considerations of the impact of $\mathrm{SH}$ across the sexes, whilst displaying clear knowledge that different sexes perpetrate and experience $\mathrm{SH}$ in complex and diverse ways. Most importantly, a discussion space that was challenging dominant hegemonic discourses of sexual behaviour across the sexes emerged. Complexities displayed within these conversations are a specific point of departure from the limited research in this area, which does not tend to explore the nuances of SH across the sexes. This study contributes to this gap.

\section{Unwanted Touching: Women to Men}

In one of the focus groups an otherwise quieter male becomes much more animated when discussing an experience of atypical SH:

Participant (Male (M)): I've shared my personal experience, do you remember? I was at the bus stop, I was on the phone and it was, like, two in the morning or three, and I was just coming home from my sister's, so I wasn't drunk or anything. And some really drunk girl just came up and hugged me and I was so uncomfortable.

Interviewer (Female (F)): Did you feel you could do anything about it?

Participant (M): I was, like, trying to walk away from her and she just sort of walked around for a bit and then came over to me and kept hugging me from behind. 
This participant has evidently talked about this before 'I've shared my personal experience' and this incident is important enough for him to remember and to recall it again here, even though he is risking violating expectations of male response (McDonald and Charlesworth 2015). As with Blunt (2015) though this sort of SH might be infrequent for men it does not mean it does not have a profound effect, in this case enough to make this participant remember this unprompted. The conversation continues with a woman in the group contributing, noting the differences in reactions to a man talking about this, where it is viewed by others as 'quite comical':

Participant (F): Like, obviously (name removed) was at a bus stop and this girl was trying to hug him and we're all, like, oh god, how did a girl do that? But we find it quite comical in a sense, like, 'oh, ha ha ha'! But actually, if it was a girl at a bus stop and a boy was coming over and constantly following her, everybody would be, like, 'whoa, that's not OK!'. There's sort of a gender bias in that.

This conversation is demonstrating a clear knowledge that sexual behaviour between the sexes is judged differently and that this demonstrates societal bias. Without naming it as such participants are challenging hegemonic stereotypes associated with men and women. Allowing continuation of this conversation is opening up their capacity for ethical subjectivity (Carmody 2009).

Another woman in the group backs this up noting an incident where a man on a television programme was 'laughed' at because his girlfriend pushed him around:

Participant (F): I was thinking the same. I don't know, even when I was watching something on (popular morning television chat show, name removed). And it was a guy and he was saying that his girlfriend pushed him or something, then all the audience laughed. If this was the other way round and it was a guy pushing a girl, then no one would be laughing. It's really weird. I don't know why it's like this, it's just society, isn't it?

A man in the group then contributes, noting that men being groped whilst doing a job of work is seen as 'acceptable':

Participant (M): Even on the radio recently with all these scandals that have been coming out, like, in the press, guys have said, like bartenders, that women will put their hands down their pants and grope them and think it's acceptable. So it isn't just men to women, it is women to men as well. I just feel like there's an issue with everyone, I personally think.

This discussion takes place within a group that knows each other well, they are friends evidently at ease with one another and this may begin to explain why there was comfort in discussing this. In the main, they demonstrated a great deal of respect for one another's opinions throughout the discussion, and also a sophisticated array of opinions regarding sexual behaviour and SH across the sexes. This level headed and respectful discussion is an example of the kinds of conversations advocated by Carmody (2009) to increase ethical subjectivity. Katz et al. (2011), 
Katz (2018) and Miller (2018) also seek to encourage social justice and transformative approaches within bystander programmes which challenge prevalent norms regarding sexual behaviour, and these extracts are examples of this.

In a different focus group one woman notes that girls also 'slap their (men's) arse or do stuff, but because it's a girl doing it to a guy it's fine'. The rest of the group agreed with this comment and this is evidence of the group questioning predominant ideologies and hegemonic norms regarding sexual behaviour between the sexes in line with transformative approaches within bystander programmes.

In a further focus group it was considered that $\mathrm{SH}$ toward men is something that is not well understood, one woman says 'knowing that men can be abused as well as women...I feel like it's such a taboo subject' and 'just making people more comfortable with it' was noted as important by this participant and others in the group agreed. Here, participants are displaying knowledge of the relational complexities of sexual behaviour between the sexes which is also indicative of developing stronger sexual ethics (Pastor 2014).

\section{Sexual Banter: Women to Men}

Sexual banter from women to men was also picked up in the focus groups:

Participant (F):We were in the gym the other day, and there was this lady and she was maybe late $50 \mathrm{~s}$ and she shouted across the gym at this guy - I mean, he was huge - shouted, 'oi, get your dick out!' And this guy was absolutely mortified. And he was just so red and he just put down his weights, grabbed his bag and left.

This is a clear example of a man who was bothered by this SH. It runs counter to predominant ideologies surrounding hegemonic ideas of male sexual behaviour which tends to ignore $\mathrm{SH}$ and SV toward men or consider that men are less bothered by this (Christmas and Seymour 2014; Blunt 2015; Zalewski et al. 2018). EverittPenhale and Ratele (2015) draw attention to how a lack of challenge to predominant toxic discourses can also contribute to their maintenance. Instead the women in this group are intelligently considering that perhaps men may also be subject to discomfort when treated in a sexually disrespectful way by women. This demonstrates listening, empathy, and consideration of alternative views in line with transformative and social justice approaches advocated in bystander programmes and indicative of 'stronger sexual ethics' (Pastor 2014) and development of greater 'ethical subjectivity' (Carmody 2009).

The next extract further explores examples of sexual behaviour that are usually associated with men as the perpetrators and women as victims:

Participant (F): Certain things girls do as well, like, we talk about guys wolfwhistling and that but I mean, girls will shout comments at guys and everything... And I feel, like, a lot of girls can be like that as well. Like, they'll make comments that you think, 'oh, if I was a guy I'd feel so awkward right now.' 
This type of open and sensitive conversation within bystander programmes may encourage reflection on a range of sexual behaviours across the sexes. A complex and complicated discussion of a more controversial and unusual subject, may enable attitudes and behaviours to be put under the microscope, held up to ethical reflection and scrutiny, challenging whole communities to question all forms of SV. Carmody (2009, p. 9) advocates for this kind of dynamic reflection which is specific to context and which can open up 'alternative possibilities and ways of being women and men.'

\section{Sexual Stereotypes: Women and Men}

One focus group holds a conversation which displays sexual stereotypes from men which are also accepted by the women in the group. This is grounded in toxic and 'traditional' notions of hegemonic masculinities which objectify women and limit female agency:

Participant (M): The thing is, when a girl does it (unwanted sexual touching), boys aren't inclined to say 'no'. Unless they find them unattractive.

Participant (M): Well, they're masculine - they don't want to say no, do they?

What if they were like, 'ugh, get off me', what does that say about them?

This extract is particularly interesting because it was not challenged by the group and in itself this is of valuable note. It demonstrates an acceptance by the men and women in this group that (1) boys or men are less likely to object to unwanted sexual touching and (2) they would only object if the girl (woman) was unattractive. This plays into a myriad of hegemonic and toxic stereotypes and if not challenged also perpetuates such discourses and underpinning ideologies (Everitt-Penhale and Ratele 2015).

The extract is also a comment made by the same focus group who previously explored unwanted sexual touching from a woman to a man as not welcome, and so is somewhat contradictory. This demonstrates confusion in both the women and men's views regarding men's responses to sexual behaviour and, as argued by Bay-Cheng (2015) contributes to arguments that a one-dimensional model of female or male sexual behaviour is inadequate. Such binary models can contribute to the maintenance of traditional models of hegemonic masculinity and femininity that contribute to SV and see relations between the sexes as adversarial (Pastor 2014; Everitt-Penhale and Ratele 2015).

The extract also plays into harmful hegemonic toxic sexual stereotypes about 'heterosexual appeal' where girls and women regarded as undesirable or unattractive are 'subject to dehumanising ridicule, pity and condescension' (Bay-Cheng 2015, p. 265). Bay-Cheng (2015) discusses the concept of sexual agency for girls and women or the extent to which ones sexual behaviour is freely chosen and self-determined and the ways in which this is policed by boys and men, girls and women. Those above the agency line are seen as in total control and controlled by no one in terms of their sexual behaviour. In order to be viewed as remaining above the agency line, others must be pushed below and those deemed unattractive are easy prey. This is such a small extract above but it conveys a strong 
message of power and control found within reactions to sexual behaviour across the sexes from both women and men. It also demonstrates a much lower level of sexual ethics (Pastor 2014). However, using a stereotype such as this and opening it up to scrutiny could impact upon a higher level of ethical subjectivity emerging for the women and the men in the group (Carmody 2009).

This was not the only example of groups' ignoring derogatory comments toward women and their sexual behaviour or sexual desirability, but space does not allow for longer consideration here. Briefly, women were at various times described as, for example, 'being bitches' (F participant), 'in boys' faces' (F participant) and only going out to 'get with someone' (M participant). These comments were not challenged by other group members either and this potentially demonstrates alignment with commonly held ideas of sexual behaviour of men and women associated with hegemonic and toxic ideologies and stereotypes.

\section{Developing Stronger Ethical Subjectivity}

The focus groups display strong knowledge that SV and $\mathrm{SH}$ from men towards women remains a greater issue and that there are different power dimensions at play. Thus, opening up such a controversial debate as atypical SH, does not necessarily mean that misrecognition of the greater levels of SV and $\mathrm{SH}$ from men to women will occur. For example, in one focus group a participant conveys clear knowledge of power differences:

Participant (F): If you've got the power of a male and a female down a dark alley, maybe, like, the woman would feel intimidated because the guy would tend to be, like, physical...It is more common to see women as the victim, I think and then the men are, like, predatory.

This participant articulates here that women may feel more 'intimidated', and that it is 'more common' to see women as victims and men as predators. This is then strengthened in sentiment by another woman in the group who quite clearly states that this is statistically known rather than just commonly understood:

Participant (F): But I think, probably from statistics, it is probably more women are more likely to be victims.

The rest of the group (men and women) agreed with this statement.

In another focus group it is also discussed how men and women were portrayed in the bystander programme and in this instance it is noted that they believe that more men perpetrate $\mathrm{SH}$ and SV than women and interestingly that if women do perpetrate it is somehow in relation to men:

Participant (M) I think men are the root of the problem and, so if a woman is involved, I think it's usually because of a man, like, a man's doing it first. So, I would rather see more efforts going to combatting it, well generally, but focused on men over women. 
This statement that women are involved in SH and SV, but only 'usually because of a man' aligns with Heidensohn's $(1985,1989,2010)$ 'double deviance' theories, where sexual behaviour outside of the feminine 'norm' is excessively punished, ignored or excused. No one else in the group challenged this assumption which plays into ideological accounts of women as pacifiers of men, a harmful stereotype across the sexes. This extract is indicative of lower levels of ethical subjectivity (Carmody 2009).

In general the focus groups demonstrate a mostly balanced approach to considering how bystander programmes might explore the issue of SV and SH across the sexes. This was often indicative of stronger sexual ethics (Pastor 2014) and higher levels of ethical subjectivity (Carmody 2009) demonstrating cognisance of a need for balance in the programmes representing women and men and the spectrum of sexual behaviour. For example in one focus group, a woman demonstrates that she thought the bystander programme she attended was not as balanced as it could be:

Participant (F): Yeah, I think it (the intervention) was one-sided. It was only giving the view of females being victims whereas, actually, males can fall into that too.

Here the participant has acknowledged a spectrum of sexual behaviour and in so doing felt the bystander programme she attended was focussed too much toward women. A participant below, in the same focus group, adds to this view, by replying:

Participant (F): I do think as well, if you get both sides, male and females, it would start a discussion. Like, it's not just one-sided because then you can have people with different views to make a discussion in the group, as opposed to just simply taking information.

It is significant here that this participant says that considering multiple sides of sexual behaviour can result in learning beyond 'simply taking information' and this aligns with the transformative and social justice models of bystander programmes, discussed by Carmody (2009), Pastor (2014), Katz et al. (2011), Katz (2018) and Miller (2018).

\section{Conclusion}

This research did not set out to specifically explore the mechanisms which may drive complicated sexual behaviour across the sexes; it sought to understand bystander programmes. However in so doing, data was clearly present in the focus group transcripts about a more nuanced consideration of $\mathrm{SH}$ across the sexes, resulting in exploration of a controversial issue of atypical SH. In some other research atypical $\mathrm{SH}$ is found but it is also found that men were unlikely to 'describe it as unpleasant' (Christmas and Seymour 2014, p. 60). This current 
study offers a point of departure from this; instead demonstrating that it can be viewed as unpleasant for men to experience this or at the least confusing and unsettling and this helps to explore and unpick sexual stereotypes which can contribute to the maintenance of SV (Pastor 2014; Everitt-Penhale and Ratele 2015).

Pastor (2014) suggests that programmes of prevention explore vulnerability across the sexes to potentially develop a stronger sexual framework for more effective prevention work and development of stronger sexual ethics. This also offers opportunities for critical thinking to emerge and for an appreciation of relational complexity (Pastor 2014) to develop. Challenging understandings of prevalent and toxic stereotypes is viewed as an integral part of more effective prevention programmes. This allows for structural processes which underlie those norms to be explored and this is aligned with social justice prevention work (Katz et al. 2011; Katz 2018; Miller 2018) where potentially increased 'ethical subjectivity' can emerge (Carmody 2009).

In highlighting that men can experience atypical $\mathrm{SH}$ from women it is critical that this does not downplay the experiences of women. Research tells us this is much more prevalent and can be much more overt, powerful and ubiquitous than that experienced by men. This current paper continues to acknowledge this imbalance in the rate and scale of SH perpetrated from men to women, and importantly, the focus groups displayed this awareness too. Therefore use of a controversial issue will not necessarily contribute to misrecognition of power and abuse, or of diversion of resources (Zalewski et al. 2018). The compassion displayed here in considering male and female experience of SH coupled with the knowledge of perpetration rates demonstrates sophisticated conversations which are at the heart of ethical subjectivity and stronger sexual ethics (Carmody 2009; Pastor 2014).

Like Bryan (2019) this can be a way to engage in 'critical counter hegemonic' understandings of men and women's sexual behaviour that moves beyond onedimensional models that can recycle old theories (Everitt-Penhale and Ratele 2015). Bryan (2019) continues by exploring in his work on black boys' play that too much attention is given to boys and violence which can reify deficit narratives. Giving attention also to those who defy dominant constructions of hegemonic ways to be a boy or a man, a girl or a women can instead begin to uncover relational aspects of sexual behaviour between the sexes. Drawing on Connell's (1995) multiple masculinities, Bryan (2019) notes that versions of masculinity are influenced by other men and by femininity; Bay-Cheng (2015) that versions of femininity are influenced by other women and masculinity. This paper contends with both of these claims.

Katz (2018, p. 1756) is clear that SV prevention work is a long way from being able to say which aspects of prevention work are 'most likely to result in significant reduction in the incidence of perpetration and victimization'. This current paper concurs and notes further research into the impact of controversial debate is needed to understand if this can be transformative.

Acknowledgements We would like to acknowledge the useful comments received upon presenting this work at the 2018 International Family Violence and Child Victimization Research Conference, as well as the suggestions from anonymous reviewers. 
Funding This work was supported by the Higher Education Funding Council for England Catalyst Fund [Project Code M05, Pass Code DIR-16-010].

\section{Compliance with Ethical Standards}

Conflict of interest No potential conflict of interest was reported by the authors.

Open Access This article is licensed under a Creative Commons Attribution 4.0 International License, which permits use, sharing, adaptation, distribution and reproduction in any medium or format, as long as you give appropriate credit to the original author(s) and the source, provide a link to the Creative Commons licence, and indicate if changes were made. The images or other third party material in this article are included in the article's Creative Commons licence, unless indicated otherwise in a credit line to the material. If material is not included in the article's Creative Commons licence and your intended use is not permitted by statutory regulation or exceeds the permitted use, you will need to obtain permission directly from the copyright holder. To view a copy of this licence, visit https://creativecommons.org/licen ses/by/4.0/.

\section{References}

Banyard, V. L. (2011). Who will help prevent sexual violence: Creating an ecological model of bystander intervention. Psychology of Violence: Special Issue on Theories of Violence, 1, 216-229.

Bassey, M. (1998). Fuzzy generalisation: An approach to building educational theory. Paper Presented at the British Educational Research Association Annual Conference, The Queen's University of Belfast, Northern Ireland, 27th-30th August 1998. Retrieved January 2019, from http://www.leeds.ac.uk/educo 1/documents/000000801.htm.

Bay-Cheng, L. Y. (2015). The agency line: A neoliberal metric for appraising young women's sexuality. Sex Roles, 73(7-8), 279-291.

Blunt, C. (2015). Male victims of sexual harassment are suffering in silence. Unilad. Retrieved January 2019, from https://www.unilad.co.uk/featured/opinion-is-sexual-harassment-really-always-a-one-way-street/.

Braun, V., \& Clarke, V. (2006). Using thematic analysis in psychology. Qualitative Research in Psychology, 3(2), 77-101.

British Educational Research Association. (2018). Ethical guidelines for educational research. Retrieved January 2019, from https://www.bera.ac.uk/researchers-resources/publications/ethical-guidelines-foreducational-research-2018.

Bryan, N. (2019). 'Playing with or like the girls': Advancing the performance of 'multiple masculinities in Black boys' childhood play' in U.S. early childhood classrooms. Gender and Education, 31(3), 309-326.

Cantor, D., Fisher, B., Chibnall, S., Harps, S., Townsend, R., Thomas, G., et al. (2019). Report on the AAU Campus Climate Survey on sexual assault and misconduct. Westat. Retrieved January 2019, from https ://www.aau.edu/sites/default/files/AAU-Files/Key-Issues/Campus-Safety/FULL_2019_Campus_Clima te_Survey.pdf.

Carmody, M. (2009). Conceptualising the prevention of sexual assault and the role of education (Vol. 10). Melbourne: Australian Centre for the Study of Sexual Assault.

Christmas, S., \& Seymour, F. (2014). Drunken nights out: Motivations, norms and rituals in the night-time economy. DrinkAware. Retrieved January 2019, from https://www.drinkaware.co.uk/media/1567/drink aware_drunken-nights-out-report_full-report_vfinal-pdf-version-without-page-breaks-_dec-2014amend.pdf.

Cohen, L., Manion, L., \& Morrison, K. (2011). Research methods in education (7th ed.). London: Routledge. Connell, R. W. (1995). Masculinities. Cambridge: Polity.

DrinkAware. (2018). 'Drunken nights out': Campaign summary. Retrieved January 2019, from https://www. drinkaware.co.uk/research/our-research-and-evaluation-reports/drunken-nights-out-campaign-summa ry/.

Equality and Human Rights Commission. (2017). Sexual harassment and the law: Guidance for employers. Retrieved January 2019, from https://www.equalityhumanrights.com/sites/default/files/sexual-haras sment-and-the-law-guidance-for-employers.pdf. 
Etikan, I., Musa, S. A., \& Alkassim, R. S. I. (2016). Comparison of convenience sampling and purposive sampling. American Journal of Theoretical and Applied Statistics, 5(1), 1-4. https://doi.org/10.11648 /j.ajtas.20160501.11.

Everitt-Penhale, B., \& Ratele, K. (2015). Rethinking 'traditional masculinity' as constructed, multiple, and \#hegemonic masculinity. South African Review of Sociology, 46(2), 4-22. https://doi.org/10.1080/21528 586.2015.1025826.

Femdal, I., \& Solbjør, M. (2018). Equality and differences: Group interaction in mixed focus groups of users and professionals discussing power. Society, Health \& Vulnerability, 9(1), 1447193. https://doi. org/10.1080/20021518.2018.1447193.

Fenton, R. A., Mott, H. L., McCartan, K., \& Rumney, P. (2014). The intervention initiative. Bristol: UWE and Public Health England.

Forsman, R. L. (2017). Prevalence of sexual assault victimization among college men, aged 18-24: A review. Journal of Evidence-Informed Social Work, 14(6), 421-432. https://doi.org/10.1080/23761 407.2017.1369204.

Heidensohn, F. (1985). Women and crime. New York: New York University Press.

Heidensohn, F. (1989). Crime and society. Hampshire, London: Macmillan.

Heidensohn, F. (2010). The deviance of women: A critique and an enquiry. British Journal of Sociology, 61, 111-126.

Higher Education Funding Council for England. (2018). Catalyst fund. Retrieved January 2019, from http:// www.hefce.ac.uk/funding/catalyst/.

Ioannou, M., Hammond, L., \& Machin, L. (2017). Male-on-male sexual assault: Victim, offender and offence characteristics. Journal of Investigative Psychology \& Offender Profiling, 14(2), 189-209. https://doi. org/10.1002/jip.1483).

Johnson, W., \& Johnson, T. (2009). Energizing learning: The instructional power of conflict. Educational Researcher, 38, 37-51.

Johnson, C. P. G., \& Otto, K. (2019). Better together: A model for women and LGBTQ equality in the workplace. Frontiers in Psychology, 10, 272. https://doi.org/10.3389/fpsyg.2019.00272.

Katz, J. (2018). Bystander training as leadership training: Notes on the origins, philosophy, and pedagogy of the Mentors in Violence Prevention model. Violence Against Women, 24(15), 17551776.

Katz, J., Heisterkamp, H. A., \& Fleming, W. M. (2011). The social justice roots of the mentors in violence prevention model and its application in a high school setting. Violence Against Women, 17, 684-702.

Kemble, C. K., \& Chettiar, I. M. (2018). Sexual assault remains dramatically underreported. Brennan Center for Justice, 4 October. Retrieved January 2019, from https://www.brennancenter.org/blog/sexual-assau lt-remains-dramatically-underreported.

McDonald, P., \& Charlesworth, S. (2015). Workplace sexual harassment at the margins. Work, Employment \& Society, 30(1), 118-134.

Miller, E. (2018). Reclaiming gender and power in sexual violence prevention in adolescence. Violence Against Women, 24(15), 1785-1793.

NIdirect. (n.d.). Sexual violence and abuse. Retrieved January 2019, from https://www.nidirect.gov.uk/artic les/sexual-violence-and-abuse.

Ochieng, N. T., Wilson, K., Derrick, C. J., \& Mukherjee, N. (2018). The use of focus group discussion methodology: Insights from two decades of application in conservation. Methods in Ecology and Evolution, 9, 20-32. https://doi.org/10.1111/2041-210x.12860.

Opinium. (2017). One in five women have been sexually harassed in the workplace. Retrieved January 2019, from https://www.opinium.co.uk/one-in-five-women-have-been-sexually-harassed-in-the-workplace/.

Pastor, N. (2014). Beyond consent: Exploring sexual violence prevention at Macalester through a framework of sexual subjectivity and sexual ethics. Retrieved January 2019, from Women's, Gender, and Sexuality Studies Honors Projects, Paper 3. http://digitalcommons.macalester.edu/wgst_honors/3.

Paulk, A., Murray, J., Hunt, A., \& Williams, Y. (2017). An assessment of campus climate among sexual minority college students. Research in Higher Education Journal, 33, 1-10.

Revolt Sexual Assault. (2018). Students' experience of sexual violence. Revolt Sexual Assault, The Student Room, Blue Marble Research. Retrieved January 2019, from https://revoltsexualassault.com/wp-conte nt/uploads/2018/03/Report-Sexual-Violence-at-University-Revolt-Sexual-Assault-The-Student-RoomMarch-2018.pdf.

White House Task Force. (2014). Not alone: The first report of the White House task force to protect students from sexual assault. Retrieved January 2019, from https://www.justice.gov/archives/ovw/page/ file/905942/download. 
World Health Organization. (2009). Violence prevention the evidence: Changing cultural and social norms that support violence. Retrieved January 2019, from https://www.who.int/violence_injury_prevention/ violence/norms.pdf.

Yung, C. R. (2015). Concealing campus sexual assault: An empirical investigation. Psychology, Public Policy and Law, 21(1), 1-9.

Zalewski, M., Drummond, P., Prügl, E., \& Stern, M. (Eds.). (2018). Sexual violence against men in global politics. Oxon: Routledge.

Publisher's Note Springer Nature remains neutral with regard to jurisdictional claims in published maps and institutional affiliations. 